\title{
RANCANG BANGUN SISTEM REKOMENDASI PEMILIHAN APARTMENT DI BEKASI
}

\author{
Sari Wulanningsih Setio ${ }^{1}$, Mira Febriana Sesunan ${ }^{2}$ \\ ${ }^{12}$ Jurusan Sistem Informasi Fakultas Teknik, Universitas Darma Persada \\ Jl. Radin Inten II (Terusan Casablanca), Pondok Kelapa, Jakarta Timur 1340 \\ mfsesunan@gmail.com
}

\begin{abstract}
ABSTACT
Apartment is a building block which is divided into a number of spaces or units that are marketed on an intermediary or leased basis. Besides the location of the apartment is usually in the middle of the city close to various centers of activity (business, entertainment, health, education). So customers must come directly to the location of the apartment and compare one apartment with another apartment. This makes it difficult for many customers to make decisions in determining the choice of apartment in bekasi. Therefore this report uses the waterfall method which includes the analysis phase, the design phase, the implementation phase, the testing phase, the maintenance phase to complete the apartment selection.this study aims to design and build a decision support system for apartment selection recommendations the reason that customers no longer need to come to the apartment one by one to ask the price, type, facilities with the system made easier to find an apartment as desired. The system implements by determining the criteria related to apartment search in bekasi which results in the customer being able to choose an apartment according to their desires that can be viewed based on the location of the apartment in bekasi.
\end{abstract}

Keywords: Apartment Selection, Apartment Rental.

\begin{abstract}
ABSTRAK
Apartment adalah blok bangunan yang dalamnya terbagi-bagi dalam sejumlah ruang atau unit yang dipasarkan secara perantara atau disewakan. Selain itu lokasi apartment biasanya ditengah kota dekat dengan berbagai pusat kegiatan (bisnis, hiburan, kesehatan, pendidikan). Sehingga customer harus datang langsung ke lokasi apartment dan membandingkan apartment yang satu dengan apartment yang lain. Hal ini membuat banyak customer kesulitan untuk mengambil keputusan dalam menentukan pilihan apartment di bekasi. Maka dari itu laporan ini menggunakan metode waterfall yang meliputi tahap analisis, tahap desain, tahap implmentasi, tahap pengujian,tahap pemeliharaan untuk menyelesaikan pemilihan apartment. Penelitian ini bertujuan untuk merancang dan membangun sistem pendukung keputusan rekomendasi pemilihan apartment alasannya agar customer tidak perlu lagi datang ke apartment satu persatu untuk menanyakan harga, tipe, fasilitas dengan adanya sistem yang dibuat mempermudahkan dalam mencari apartment sesuai keinginan. Sistem mengimplementasikan dengan menentukan kriteria yang berkaitan dengan pencarian apartment di bekasi yang menghasilkan customer dapat memilih apartment sesuai dengan keinginan yang dapat di lihat status berdasarkan dari lokasi apartment yang ada di bekasi.
\end{abstract}

Kata kunci : Apartment Seleksi, Apartment Rental 


\section{PENDAHULUAN}

Sejalan dengan perkembangan teknologi yang semakin modern, banyak Apartemenapartemen yang menggunakan fasilitas internet dalam sistem pemesanan atau pemilihan apartemen. Hal ini dipandang memiliki beberapa keuntungan lain bila dibandingkan dengan sistem pemesanan apartemen atau pemilihan secara langsung, maka akan mempengaruhi perilaku dari Apartemen tersebut baik dari segi manajemen maupun pemesanan dan layanan informasi yang diberikan.

Dalam menentukan pemilihan apartment yang tepat dan sesuai dengan keinginan tentunya bukanlah hal yang sangat mudah, setidaknya ada beberapa kriteria yang digunakan dalam pemilihan apartment, diantaranya seperti jarak ,fasilitas umum, harga unit, keamanan, dan tipe. Alasan masyarakat mempertimbangkan faktor harga unit karena hal tersebut berkaitan dengan pendapatan mereka. Dengan fasilitas yang lengkap maka customer menetapkan pilihannya dengan perasaan puas dan senang. Berbagai pertimbangan sangat penting agar tidak menyesal dikemudian hari, agar tidak banyak customer yang kurang cocok setelah menyewa apartement. (Akmal, 2007)

\section{METODOLOGI PENELITIAN}

Berikut ini merupakan tahapan-tahapan dalam metode pengembangan sistem yang digambarkan dibawah ini :(Bassil, 2012)

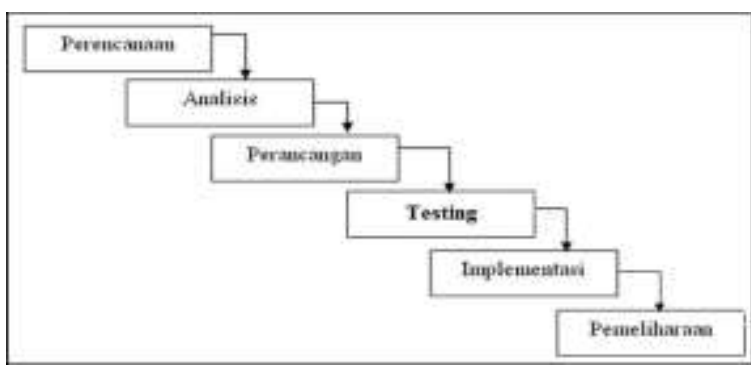

Gambar 1. Metode Waterfall

Pada tahapan ini terdapat beberapa poin penting dalam pembuatan aplikasi sistem Rekomendasi Pemilihan Apartment Di Bekasi adalah sebagai berikut :

\section{Tahap Analisis}

Tahap ini pengembang sistem diperlukan komunikasi yang bertujuan untuk memahami perangkat lunak yang diharapkan oleh pengguna dan batasan perangkat lunak tersebut. Informasi ini biasanya dapat diperoleh melalui wawancara, diskusi atau survei langsung. Informasi dianalisis untuk mendapatkan data yang dibutuhkan oleh pengguna.

\section{Tahap Desain}

Spesifikasi kebutuhan dari tahap sebelumnya akan dipelajari dalam fase ini dan desain sistem disiapkan. Desain Sistem membantu dalam menentukan perangkat keras (hardware) dan sistem persyaratan dan juga membantu dalam mendefinisikan arsitektur sistem secara keseluruhan. 


\section{Tahap Implementasi}

Pada tahap ini, sistem pertama kali dikembangkan di program kecil yang disebut unit, yang terintegrasi dalam tahap selanjutnya. Setiap unit dikembangkan dan diuji untuk fungsionalitas yang disebut sebagai unit testing.

\section{Tahap Pengujian}

Seluruh unit yang dikembangkan dalam tahap implementasi diintegrasikan ke dalam sistem setelah pengujian yang dilakukan masing-masing unit. Setelah integrasi seluruh sistem diuji untuk mengecek setiap kegagalan maupun kesalahan

\section{Tahap Pemeliharaan}

Tahap akhir dalam model waterfall, Perangkat lunak yang sudah jadi, dijalankan serta dilakukan pemeliharaan. Pemeliharaan termasuk dalam memperbaiki kesalahan yang tidak ditemukan pada langkah sebelumnya. Perbaikan implementasi unit sistem dan peningkatan jasa sistem sebagai kebutuhan baru.

\section{HASIL DAN PEMBAHASAN}

\section{Rancangan Tampilan Login}

Pada halaman awal terdapat form login digunakan unutk akses masuk untuk Sales dan User. Form login tersebut juga digunakan pengguna lainnya untuk masuk ke akun yang mereka miliki.

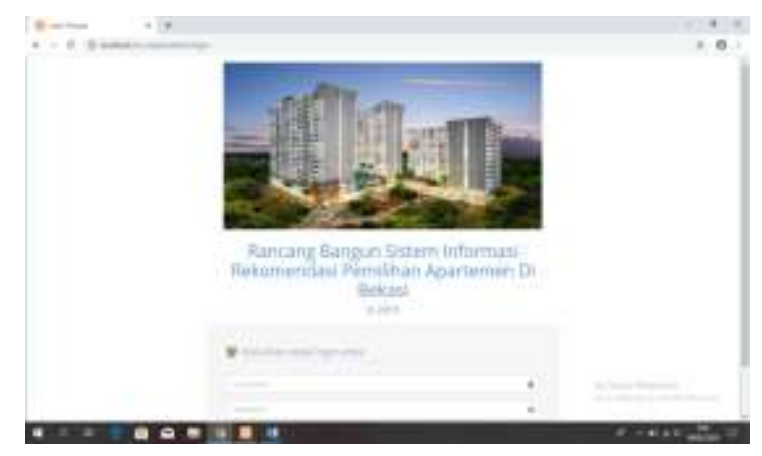

Gambar 2. Tampilan awal login

\section{Rancangan Tampilan Awal Sales}

Halaman ini merupakan tampilan awal ketika Sales sudah login. Didalam menu utama terdapat menu menu yang dapat di akses oleh sales.

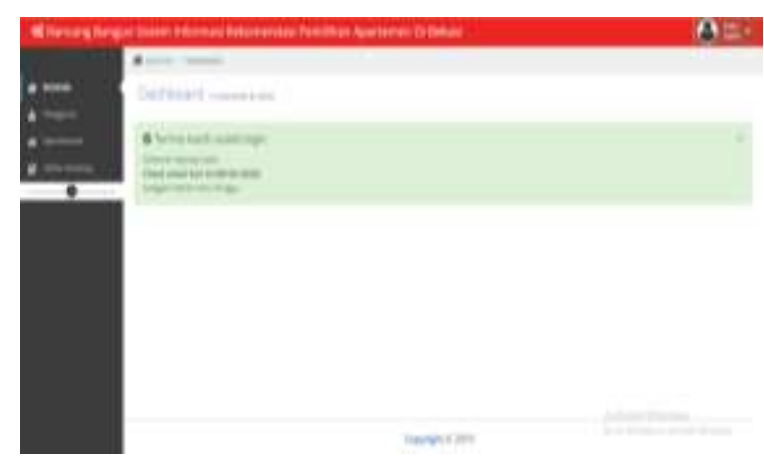

Gambar 3. Rancangan tampilan data sales

\section{RancanganTampilan Data Sales}

Halaman ini merupakan tampilan halaman menu data pengguna yang di dalamnya terdapat list pengguna, dan terdapat fungsi tambah, hapus dan ubah. Berikut implmentasi halaman data pengguna. 


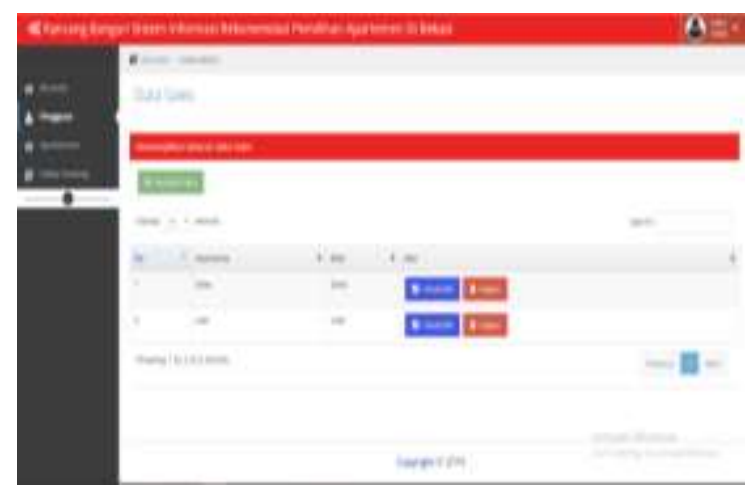

Gambar 4. Halaman Menu Pengguna

\section{Rancangan Tampilan Data Apartement}

Halaman ini merupakan tampilan halaman data apartement yang di dalamnya terdapat list data apartement, dan terdapat fungsi tambah, hapus dan ubah. Berikut implmentasi halaman data apatement.

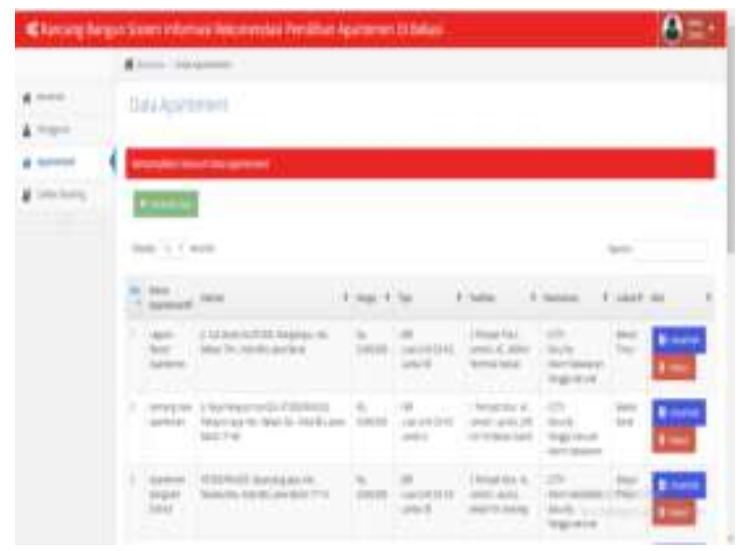

Gambar 5. Rancangan Tampilan Data

Apartment

\section{Rancangan Tampilan Daftar Booking}

Halaman ini merupakan Daftar Booking di halaman sales, jika Tamu sudah memilih apartment yang dipilih sesuai kriteria maka sales akan menerima pemberitahuan dan akan menyetujui/ tidak yang akan masuk ke tamu yang memesan.

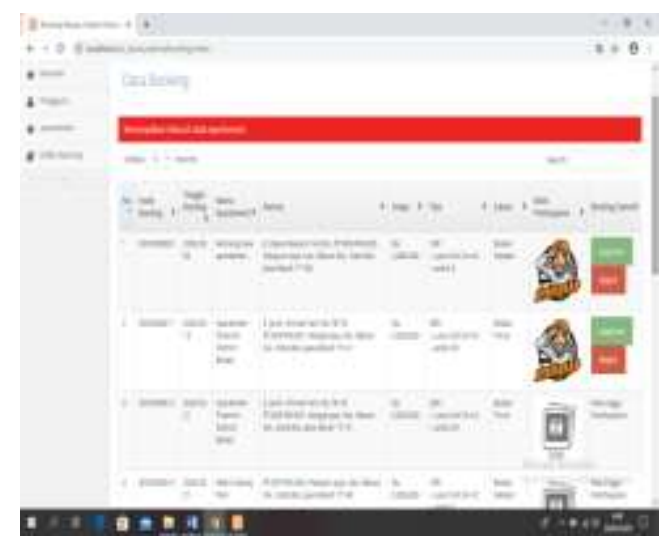

Gambar 6. Rancangan Tampilan Daftar Booking

\section{Tampilan Hak akses User}

Tampilan Menu utama

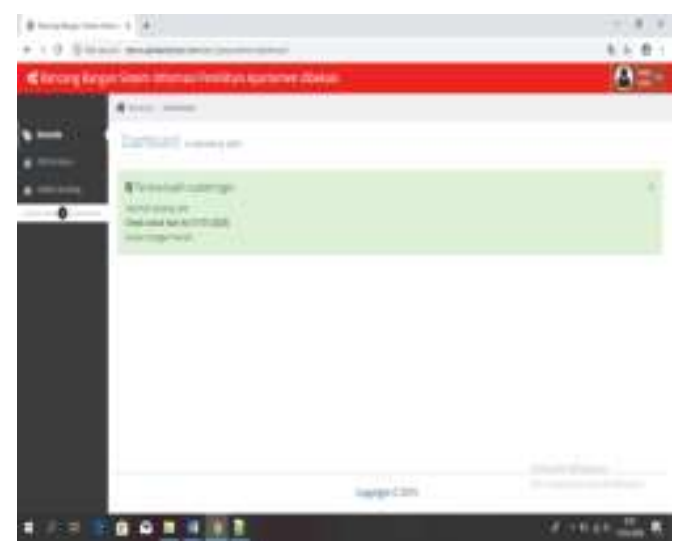

Gambar 7. Tampilan Menu Utama

\section{Tampilan Kriteria User}

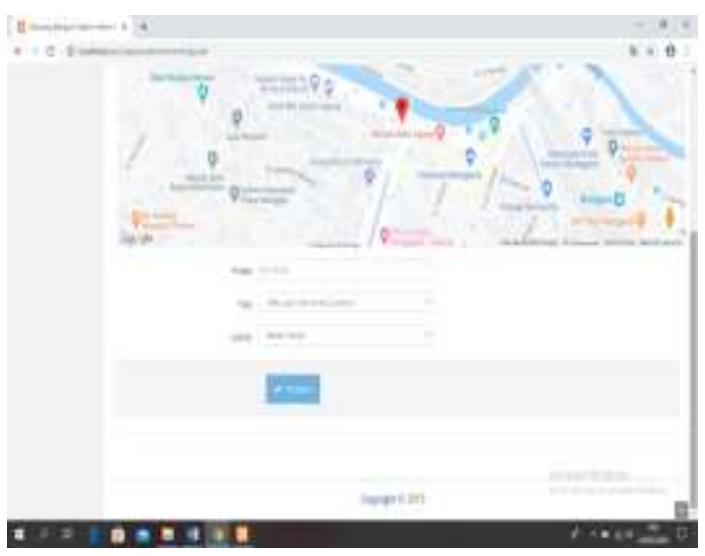

Gambar 8. Halaman Kriteria User 


\section{Tampilan Daftar Booking User}
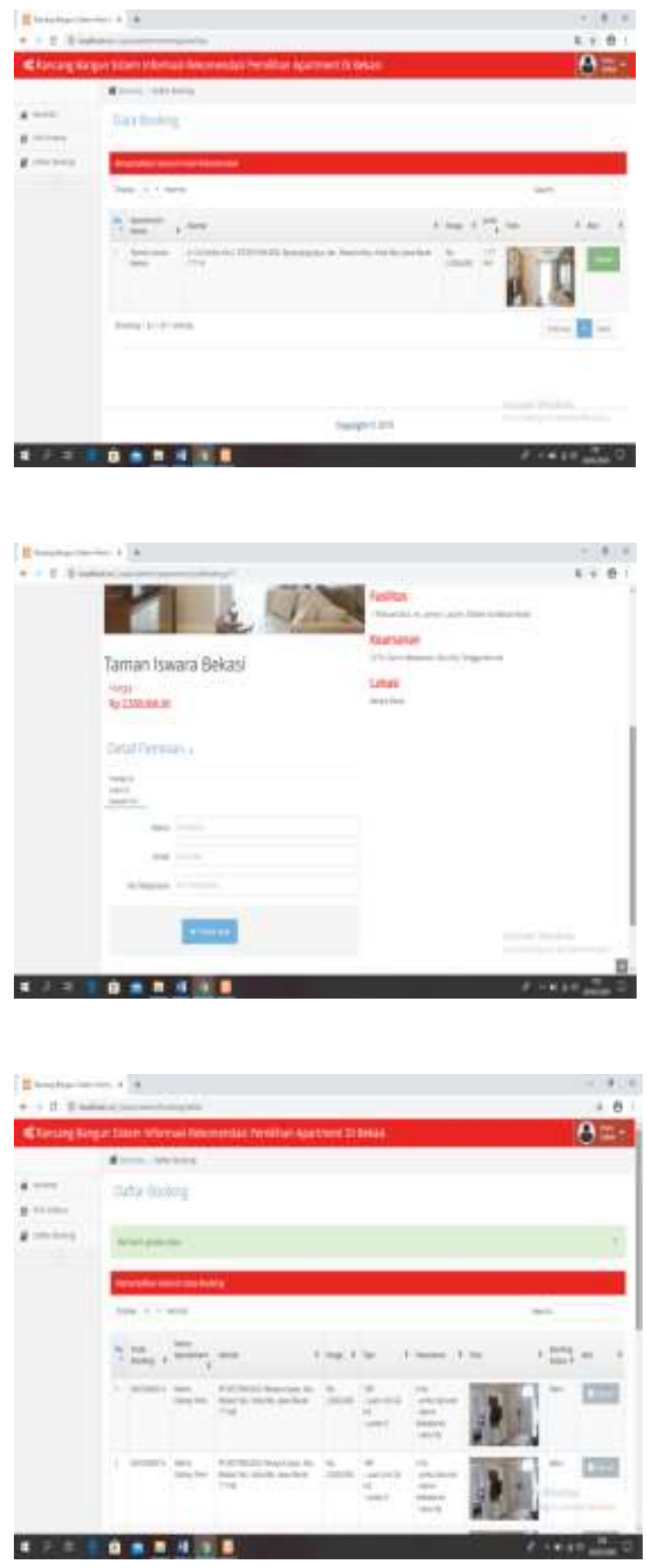

Gambar 9. Halaman Daftar Booking User

\section{SIMPULAN}

1. Hasil dari aplikasi ini akan mampu membantu customer dalam menentukan pemilihan apartment di bekasi yang di inginkan sesuai dengan kriteria dan menampilkan profil apartment sehingga tamu tidak salah dalam memilih apartment.

2. Memudahkan tamu dalam sistem penyewaan kamar dengan cara profil apartment ditulis secara detail sehingga tamu dapat mengetahui apartment sesuai dengan kriteria agar tidak salah dalam bertransaksi.

\section{DAFTAR PUSTAKA}

[1] Akmal, I. (2007). Menata apartemen: Gramedia Pustaka Utama

[2] Bassil. (2012). PenjelasanMetode Waterfall: Graha Ilmu.

[3] Black and Champion. (2014:3). Pengertian Blackbox. Graha Ilmu.

[4] Flowler, Martin. (2005:141). Permodelan Use Case: Graha Ilmu.

[5] Flowler, Martin. (2005:163). Permodelan Activity Diagram: Graha Ilmu.

[6] HM, Jogiyanto. 2005. Analisa dan Desain Sistem Informasi. Yogyakarta: Andi.

[7] HM, Jogiyanto. 2005. Kualitas dari suatu sistem Informasi Yogyakarta: Andi.

[8] HM, Jogiyanto. (1989:10). Analisa dan Desain Sistem Informasi 
[9] Pendekatan Terstruktur. Yogyakarta: Andi

[10] Kadir. (2014). PenjelasanHypertext Preprocessor: Yogyakarta.

[11] Munawar. 2005. Permodelan Visual Menggunakan UML. Yogyakarta:

[12] Mulyanto, Irawan. (2009:133.Konsep Dasar Web: PT. Gramedia: Jakarta

[13] Nugroho, Adi. (2010:6). PengertianUnified Modeling Language: Yogyakarta.

[14] Subakti. (2002). Komponen DSS : Bandung .

[15] Yakub. (2012). Pengantar Sistem Informasi. Yogyakarta: Graha Ilmu.

[16] Ardiansyah, R. (2019, November). Penggunaan Metode Balance Scorecard Untuk Mengukur Kinerja Pekerjaan Pada PT. Bangun Cipta Karya Pamungkas (PT. BCKP). In Prosiding Seminar Nasional Darmajaya (Vol. 1, pp. 78-87). 